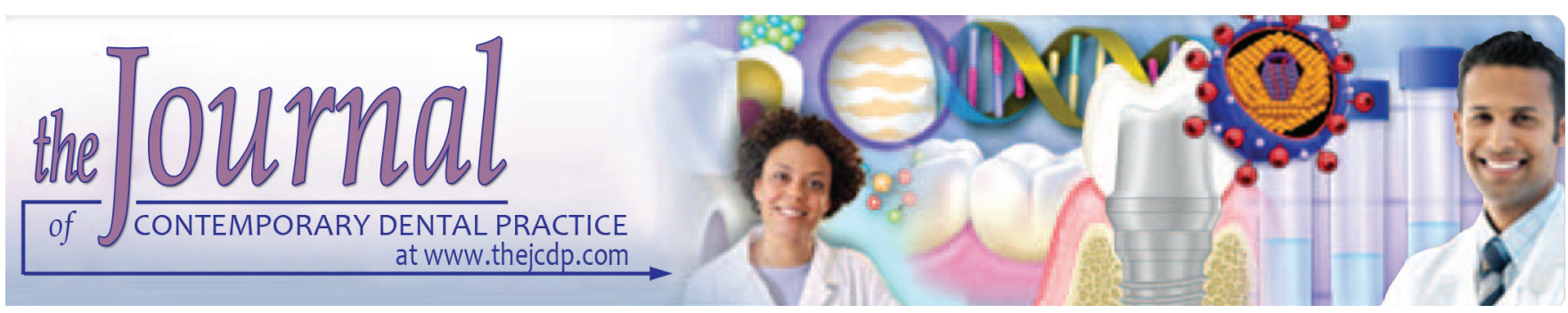

\title{
Wear Resistance of Bulk-fill Composite Resin Restorative Materials Polymerized under different Curing Intensities
}

Fahad Alkhudhairy

\begin{abstract}
Introduction: The aim of this study was to assess the wear resistance of four bulk-fill composite resin restorative materials cured using high- and low-intensity lights.

Materials and methods: Twenty-four samples were prepared from each composite resin material (Tetric N-Ceram, SonicFill, Smart Dentin Replacement, Filtek Bulk-Fill) resulting in a total of 96 samples; they were placed into a mold in a single increment. All of the 96 samples were cured using the Bluephase $\mathrm{N}$ light curing unit for 20 seconds. Half of the total specimens $(n=48)$ were light cured using high-intensity output $\left(1,200 \mathrm{~mW} / \mathrm{cm}^{2}\right)$, while the remaining half $(n=48)$ were light cured using low-intensity output $\left(650 \mathrm{~mW} / \mathrm{cm}^{2}\right)$. Wear was analyzed by a three-dimensional (3D) noncontact optical profilometer (Contour GT-I, Bruker, Germany). Mean and standard deviation (SD) of surface loss (depth) after 120,000 cycles for each test material was calculated and analyzed using one-way analysis of variance (ANOVA) with a significance level at $p<0.05$.
\end{abstract}

Results: The least mean surface loss was observed for SonicFill $(186.52 \mu \mathrm{m})$ cured using low-intensity light. No significant difference in the mean surface loss was observed when comparing the four tested materials with each other without taking the curing light intensity into consideration ( $p=0.352)$. A significant difference in the mean surface loss was observed between SonicFill cured using high-intensity light compared with that cured using low-intensity light $(p<0.001)$

Conclusion: A higher curing light intensity $\left(1,200 \mathrm{~mW} / \mathrm{cm}^{2}\right)$ had no positive influence on the wear resistance of the four bulk-fill composite resin restorative materials tested compared with lower curing light intensity $\left(650 \mathrm{~mW} / \mathrm{cm}^{2}\right)$. Furthermore, SonicFill cured using low-intensity light was the most wearresistant material tested, whereas Tetric $\mathrm{N}$-Ceram cured using high-intensity light was the least wear resistant.

Department of Restorative Dental Sciences, College of Dentistry King Saud University, Riyadh, Kingdom of Saudi Arabia

Corresponding Author: Fahad Alkhudhairy, Department of Restorative Dental Sciences, College of Dentistry, King Saud University, Riyadh, Kingdom of Saudi Arabia, e-mail: dr_fahad9@outlook.com
Clinical significance: The wear resistance was better with the newly introduced bulk-fill composite resins under low-intensity light curing.

Keywords: Bulk-fill, Composites, Light intensity, Wear resistance.

How to cite this article: Alkhudhairy F. Wear Resistance of Bulk-fill Composite Resin Restorative Materials Polymerized under different Curing Intensities. J Contemp Dent Pract 2017;18(1):39-43.

Source of support: Nil

Conflict of interest: None

\section{INTRODUCTION}

Composite resin has gained importance and popularity as a restorative material of choice, mainly due to its excellent esthetic properties. However, a relatively poor wear resistance had contributed to the failure of composite resin restorations clinically. ${ }^{1}$ Wear of composite resin may depend on factors, such as the concentration and size of filler particles ${ }^{2}$ and resin formulation. ${ }^{3}$ Finer particles for a fixed volume fraction of filler may result in decreased interparticle space, leading to reduced wear resistance. ${ }^{4,5}$ Another study reported that increasing resin viscosity may lead to decrease in wear resistance. ${ }^{6}$ Furthermore, the quality of the interfacial bond between the fillers and the matrix and the extent of the curing of the resin matrix may also influence the wear resistance of composite resin restorations. ${ }^{7,8}$ Wear resistance is vital for the longevity of restoration and maintenance of a stable occlusal contact over time. ${ }^{9}$ Dental restorations should ideally have wear resistances similar to that of natural tooth. ${ }^{3}$

Several studies have investigated the influence of different methods of curing on the wear resistance of commercially available composite resin materials. Heatcured composite was found to exhibit less wear in vivo than a chemically cured version of the same formulation. ${ }^{10}$ 
No differences in the clinical wear rates were reported in a study that compared the clinical wear of light-cured occlusal inlays with that of light-cured and heat-treated occlusal inlays. ${ }^{11}$ The wear rate of light-cured Brilliant DI inlays was found to be similar when used as an inlay or as a direct restorative material. ${ }^{12} \mathrm{Ch}$ arisma ${ }^{\circledR}$, used as an inlay, was found to have a reduced wear rate after being subjected to a heat treatment at $110^{\circ} \mathrm{C}$ compared with the light-cured material. ${ }^{13}$ Furthermore, several other studies have investigated the wear resistance of commercially available packable composites. One study reported higher wear values for packable composites compared with hybrid composites. ${ }^{14}$ On using the Leinfelder clinical wear simulator, the estimated 3-year wear of Prisma TPH was reported to be the highest compared with Solitaire, ALERT, while the least wear was reported for SureFil. ${ }^{15}$ On the contrary, the wear of Solitaire was reported to be the highest compared with SureFil, ALERT, and Z100, using a Davidson/de Gee wear tester. ${ }^{16}$ Another study reported that SureFil and Herculite wore less compared with Solitaire and ALERT, using a Leinfelder clinical wear apparatus. ${ }^{17}$

A limitation in the depth of cure and the likelihood of insufficient monomer conversion at depth were stated as major concerns associated with conventional light-cured composite resins. ${ }^{18}$ Bulk-fill materials, on the contrary, promote light transmittance, which enables them to achieve a depth of cure in excess of
$4 \mathrm{~mm} \cdot{ }^{19,20}$ Micromechanical properties, such as indentation modulus, Vickers hardness, and macromechanical properties, such as flexural strength and flexural modulus of different bulk-fill resin-based composites have been assessed. $^{21,22}$ Furthermore, Vickers hardness, depth of cure, and indentation modulus of bulk-fill resin-based composites assessed at varying depths, irradiation times, and distances from the light tip have also been reported. ${ }^{23}$ However, the influence of different curing intensities on the wear resistance of bulk-fill composite resin has not been studied till date. Therefore, the aim of this study was to assess the wear resistances of four different commercially available bulk-fill composite resin restorative materials cured using high- and low-intensity lights.

\section{MATERIALS AND METHODS}

The present study was registered at and approved by the College of Dentistry Research Center (Registration number: FR 0321). The four bulk-fill materials used in this study are presented in Table 1 . Twenty-four samples were prepared from each composite resin material, resulting in a total of 96 samples, using a two-part split brass metal mold with a diameter of $5 \mathrm{~mm}$ and a thickness of $4 \mathrm{~mm}$. This ensured the standardization of the shape and size of each sample. A clear Mylar strip (Mylar Uni-strip, Caulk/Dentsply, Milford, DE, USA) was placed on top of a clean glass slab after which the split brass mold was placed atop the strip and a sufficient amount of restorative

Table 1: Characteristics of materials tested

\begin{tabular}{|c|c|c|c|}
\hline Materials & Composition & Shade & Manufacturer \\
\hline Tetric N-ceram & $\begin{array}{l}\text { Monomer matrix: } \\
\text { Dimethacrylates (19-21\% weight) } \\
\text { Fillers: } \\
\text { Barium glass, perpolymer, ytterbium trifluoride and mixed oxide }\end{array}$ & IV A & $\begin{array}{l}\text { Ivoclar Vivadent, Schaan/ } \\
\text { Liechtenstein }\end{array}$ \\
\hline $\begin{array}{l}\text { SonicFill, } \\
\text { nanohybrid } \\
\text { composite } \\
\text { restorative }\end{array}$ & $\begin{array}{l}\text { Resin matrix: } \\
\text { (1-methylethylidene) bis (4, 1-phenyleneoxy-2, 1-ethanediyloxy-2, } \\
\text { 1-ethanediyl) bismethacrylate. (1-methylethylidene) bis [4, 1-phenyleneoxy } \\
\text { (2-hydroxy-3, 1-propanediyl)] bismethacrylate, 2, 2'-rthylenedioxydiethyl } \\
\text { dimethacrylate } \\
\text { Fillers: } \\
\text { Glass, oxide, and silicon dioxide }\end{array}$ & $\mathrm{A} 2$ & $\begin{array}{l}\text { Kerr Corporation, Orange, } \\
\text { CA, USA }\end{array}$ \\
\hline $\begin{array}{l}\text { Smart dentin } \\
\text { replacement }\end{array}$ & $\begin{array}{l}\text { Resin matrix: } \\
\text { Modified urethane dimethacrylate resin, Ethoxylated Bisphenol A } \\
\text { dimethacrylate (EBPADMA), Triethyleneglycol dimethacrylate (TEGDMA) } \\
\text { Fillers: } \\
\text { Barium-alumino-fluoro-borosilicate glass, strontium alumino-fluoro-silicate } \\
\text { glass }\end{array}$ & A2 & $\begin{array}{l}\text { DENTSPLY Caulk, Milford, } \\
\text { USA }\end{array}$ \\
\hline $\begin{array}{l}\text { Filtek bulk- } \\
\text { fill, posterior } \\
\text { restorative }\end{array}$ & $\begin{array}{l}\text { Resin matrix: } \\
\text { AUDMA, UDMA, and 1,12-dodecane-DMA } \\
\text { Fillers: } \\
\text { Nonagglomerated/nonaggregated } 20 \text {-nm silica filler, a nonagglomerated/ } \\
\text { nonaggregated } 4 \text { to } 11 \mathrm{~nm} \text { zirconia filler, an aggregated zirconia/silica } \\
\text { cluster filler ( } 20 \mathrm{~nm} \text { silica and } 4 \text { to } 11 \mathrm{~nm} \text { zirconia particles), and a ytterbium } \\
\text { trifluoride filler consisting of agglomerate } 100 \mathrm{~nm} \text { particles }\end{array}$ & A2 & $\begin{array}{l}\text { 3M ESPE, St. Paul, MN, } \\
\text { USA }\end{array}$ \\
\hline
\end{tabular}


composite material was placed into the mold using a plastic material and then condensed. The composite resin was placed into the mold in a single increment. Likewise, the upper surface of the composite resin was covered with a clear Mylar strip, and a 1-mm-thick glass slide was placed on top of it and then gently pressed to remove excess material on the mold. To prevent the formation of an oxygen-inhibited area and ensure smooth and flat surfaces, Mylar strips were placed on either side of the mold during curing. The material was light cured using a light-emitting diode light-curing unit (Bluephase $\mathrm{N}$, Ivoclar Vivadent). Power intensity was measured using a dental Bluephase ${ }^{\circledR}$ radiometer (Ivoclar Vivadent).

The specimen was, thereafter, gently removed from the mold, and the bottom surface of the specimen was marked with a permanent marker (Japan) to facilitate identification. The same procedure was done to complete the total number of samples. All of the 96 samples were cured using the Bluephase $\mathrm{N}$ light-curing unit for 20 seconds. Half of the total number of specimens $(n=48)$ were light cured using high-intensity output $\left(1,200 \mathrm{~mW} / \mathrm{cm}^{2}\right)$, while the remaining half $(\mathrm{n}=48)$ were light cured using low-intensity output $\left(650 \mathrm{~mW} / \mathrm{cm}^{2}\right)$. Any form of additional polishing can lead to an increase in surface roughness, and hence, no polishing of the samples was carried out.

After 24 hours, each sample was mounted into an acrylic block, and a baseline surface roughness of the specimens was analyzed by a three-dimensional (3D) noncontact optical profilometer (Contour GT-I, Bruker, Germany) and expressed as $\mu \mathrm{m}$ Sa value. All specimens were mounted on an acrylic block to facilitate mechanical testing using a chewing simulator CS-4.8 (SD Mechatronik $\mathrm{GmbH}$, Germany). Stainless steel balls served as antagonistic specimens. Specimens were dynamically loaded in a dual-axis chewing simulator with a load of $40 \mathrm{~N}$ for 120,000 cycles at a frequency of $1.6 \mathrm{~Hz}$. Wear assessment was analyzed using the profilometer.

The data obtained from the study were manually entered into a Statistical Package for the Social Sciences (SPSS) database (IBM, SPSS version 20, IL, USA) and analyzed with a significance level established at $\mathrm{p}<0.05$. Mean and SD of surface loss (depth) after 120,000 cycles for each test material were calculated and analyzed using one-way analysis of variance (ANOVA). Post hoc tests were performed for multiple comparisons and independent samples. The t-test was used for comparisons within each group.

\section{RESULTS}

The mean surface loss $(\mu \mathrm{m})$ of each test material distributed according to two different curing light intensities is given in Table 2. The highest mean surface loss was observed for Tetric N-Ceram $(491.20 \mu \mathrm{m})$ followed by SonicFill $(473.60 \mu \mathrm{m})$ - both cured using high-intensity light. The least mean surface loss was observed for SonicFill $(186.52 \mu \mathrm{m})$ cured using low-intensity light. A very highly significant difference in the mean surface loss was observed between SonicFill cured using high-intensity light compared with that cured using low-intensity light $(\mathrm{p}<0.001)$. Furthermore, a highly significant difference in the mean surface loss was observed between Tetric $\mathrm{N}$-Ceram cured using high-intensity light compared with that cured using low-intensity light $(\mathrm{p}=0.001)$.

No significant difference in the mean surface loss was observed when comparing the four tested materials with each other without taking the curing light intensity into consideration $(\mathrm{p}=0.352)$ and when comparing the four tested materials cured using high-intensity light $(p=0.469)$. However, a significant difference in the mean surface loss was observed when comparing the four tested materials cured using low-intensity light ( $\mathrm{p}=0.009$ ). Post hoc tests revealed that significant differences in wear values of materials cured using low intensity were found between SonicFill and Smart Dentin Replacement $(\mathrm{p}=0.016)$ and Filtek Bulk-Fill $(\mathrm{p}=0.019)$.

\section{DISCUSSION}

The wear resistance of four bulk-fill composite resin restorative materials cured using high- and low-intensity light was evaluated in this in vitro study. The results showed that SonicFill cured using low-intensity light

Table 2: Mean surface loss $(\mu \mathrm{m})$ of each test material distributed according to two different curing light intensities

\begin{tabular}{|c|c|c|c|c|c|}
\hline Materials & $\begin{array}{l}\text { Curing } \\
\text { intensity }\end{array}$ & $\begin{array}{l}\text { Number of } \\
\text { specimens }\end{array}$ & Mean & $S D$ & $p$-value \\
\hline \multirow[t]{2}{*}{ Tetric N-Ceram } & High & 12 & 491.20 & 110.30 & $0.001^{*}$ \\
\hline & Low & 12 & 275.70 & 157.70 & \\
\hline \multirow[t]{2}{*}{ SonicFill } & High & 12 & 473.60 & 132.60 & $<0.001^{* *}$ \\
\hline & Low & 12 & 186.52 & 72.44 & \\
\hline \multirow[t]{2}{*}{ Smart Dentin Replacement } & High & 12 & 413.70 & 76.04 & 0.229 \\
\hline & Low & 12 & 356.35 & 141.27 & \\
\hline \multirow[t]{2}{*}{ Filtek Bulk-Fill } & High & 12 & 470.43 & 165.97 & 0.079 \\
\hline & Low & 12 & 353.19 & 144.87 & \\
\hline
\end{tabular}

*significant; **highly significant 
was the most wear-resistant material tested, whereas Tetric N-Ceram cured using high-intensity light was the least wear resistant.

In vitro studies do not simulate the exact oral environment, but these studies are important in predicting the clinical performance of the latest restorative materials. ${ }^{24}$ Several methodologies have been developed and used for testing wear resistance of composite resin materials. Some of these include the materials testing and simulation artificial oral environment, the Academisch Centrum for Tandheelkunde Amsterdam wear machine, the University of Alabama wear machine, and the Oregon Health Science University oral wear simulator. ${ }^{25-28}$ The determination of the mean total volumetric wear has been reported to be more accurate compared with mean maximum wear depth measurements in evaluating material loss due to wear. ${ }^{29}$ The present study measured the mean maximum wear depth using a 3D noncontact optical profilometer, although some studies ${ }^{29,30}$ have cited difficulties in reporting the mean maximum wear depth measurements.

Apart from the concentration and size of filler particles and resin formulation which affects wear properties, the longevity of composite resin restorations is related to satisfactory curing procedures. ${ }^{2,3,31}$ Inefficient curing procedures may lead to low degree of conversion, increased cytotoxicity, reduced hardness and strength, low modulus of elasticity, decreased wear resistance, marginal microleakage, and bond failure. ${ }^{32}$ Increasing curing light intensity may improve polymerization degree, increase curing depth, and will require shorter irradiation time. ${ }^{33,34}$

The degree of conversion has also been considered vital for the clinical success of resin-based composite restorative materials and has been linked with the values of mechanical properties, biocompatibility, and color stability. ${ }^{35,36}$ The degree of conversion may be affected by a reduction in light penetration, which may be attributed to light scattering at particle interfaces ${ }^{36}$ and light absorbance by photoinitiators and pigments. ${ }^{37}$ Shade, monomeric reactivity, and refractive index mismatch may also reduce the degree of conversion. ${ }^{38}$ Furthermore, a reduction in the light-cure unit output intensity may reduce the degree of conversion at different depths of the resin-based composite material from the unit, ensuing higher susceptibility to wear. ${ }^{39}$ This has led the author of the present study to theorize that a higher curing light intensity $\left(1,200 \mathrm{~mW} / \mathrm{cm}^{2}\right)$ will improve the wear resistance of bulk-fill composite materials when compared with lower curing light intensity $\left(650 \mathrm{~mW} / \mathrm{cm}^{2}\right)$.

A study by Halvorson et $\mathrm{al}^{40}$ reported that a nearmaximum degree of conversion of conventional resinbased composite materials could be achieved at the irradiated surface with low irradiances and short exposure times. A10-second exposure at an intensity of $200 \mathrm{~mW} / \mathrm{cm}^{2}$ was sufficient to achieve $90 \%$ of the conversion. Furthermore, the authors found no significant differences in the mean total volumetric wear and mean maximum wear depth when the tested materials were irradiated at intensities of $650 \pm 14$ and $150 \pm 8 \mathrm{~mW} / \mathrm{cm}^{2}$, although some differences were identified between each resinbased composite material tested. The present study found no significant difference in the mean surface loss when comparing the four tested bulk-fill materials with each other without taking the curing light intensity into consideration and when comparing the four tested materials cured using high-intensity light $\left(1,200 \mathrm{~mW} / \mathrm{cm}^{2}\right)$. However, a significant difference in the mean surface loss was observed when comparing the four tested materials cured using low-intensity light $\left(650 \mathrm{~mW} / \mathrm{cm}^{2}\right)$.

Certain limitations of this study need to be mentioned when discussing the results. Firstly, the mean maximum wear depth was measured using a 3D noncontact optical profilometer, which has been reported to be less accurate compared with measuring the mean total volumetric wear in evaluating material loss due to wear. ${ }^{29}$ A standardized protocol needs to be followed in the methodologies used to test wear resistance of dental materials and the reporting of the results pertaining to depth, area, or volume. ${ }^{41}$ Secondly, the influences of different curing times on wear resistance of the materials at two different curing intensities were not assessed. All materials tested, both at high and low intensities, were cured for 20 seconds.

\section{CONCLUSION}

Within the limitations, the following conclusions may be drawn:

- Higher curing light intensity $\left(1,200 \mathrm{~mW} / \mathrm{cm}^{2}\right)$ had no positive influence on the wear resistance of the four bulk-fill composite resin restorative materials tested compared with lower curing light intensity $\left(650 \mathrm{~mW} / \mathrm{cm}^{2}\right)$.

- SonicFill cured using low-intensity light was the most wear-resistant material tested, whereas Tetric $\mathrm{N}$-Ceram cured using high-intensity light was the least wear resistant.

\section{REFERENCES}

1. Hickel R, Manhart J. Longevity of restorations in posterior teeth and reasons for failure. J Adhes Dent 2001 Spring;3(1):45-64.

2. Turssi CP, De Moraes Purquerio B, Serra MC. Wear of dental resin composites: insights into underlying processes and assessment methods - a review. J Biomed Mater Res B Appl Biomater 2003 May;65(2):280-285.

3. Lambrechts P, Braem M, Vuylsteke-Wauters M, Vanherle G. Quantitative in vivo wear of human enamel. J Dent Res 1989 Dec;68(12):1752-1754. 
4. Soderholm KJ, Richards ND. Wear resistance of composites: a solved problem? Gen Dent 1998 May-Jun;46(3):256-263, quiz 264-255.

5. Turssi CP, Ferracane JL, Vogel K. Filler features and their effects on wear and degree of conversion of particulate dental resin composites. Biomaterials 2005 Aug;26(24):4932-4937.

6. Musanje L, Ferracane JL, Ferracane LL. Effects of resin formulation and nanofiller surface treatment on in vitro wear of experimental hybrid resin composite. J Biomed Mater Res B Appl Biomater 2006 Apr;77(1):120-125.

7. Ferracane JL, Mitchem JC, Condon JR, Todd R. Wear and marginal breakdown of composites with various degrees of cure. J Dent Res 1997 Aug;76(8):1508-1516.

8. Shi G, Zhang MQ, Rong MZ, Wetzel B, Friedrich K. Sliding wear behavior of epoxy containing nano-Al2O3 particles with different pretreatments. Wear 2004 Jun;256(11-12): 1072-1081.

9. Zhi L, Bortolotto T, Krejci I. Comparative in vitro wear resistance of CAD/CAM composite resin and ceramic materials. J Prosthet Dent 2016 Feb;115(2):199-202.

10. Lutz F, Phillips RW, Roulet JF, Setcos JC. In vivo and in vitro wear of potential posterior composites. J Dent Res 1984 Jun;63(6):914-920.

11. Wendt SL Jr, Leinfelder KF. The clinical evaluation of heat-treated composite resin inlays. J Am Dent Assoc 1990 Feb;120(2):177-181.

12. Scheibenbogen-Fuchsbrunner A, Manhart J, Kremers L, Kunzelmann KH, Hickel R. Two-year clinical evaluation of direct and indirect composite restorations in posterior teeth. J Prosthet Dent 1999 Oct;82(4):391-397.

13. Leinfelder KF, Broome JC. In vitro and in vivo evaluation of a new universal composite resin. J Esthet Dent 1994;6(4): 177-183.

14. Knobloch L, Kerby R, Seghi R. Wear resistance of posterior condensable composite resins. J Dent Res 1999;78:447.

15. Suzuki S. In vitro wear of condensable resin composite restoratives. J Dent Res 1999;78(447).

16. Dang H, Sarrett D. Wear behavior of flowable and condensable composite resins. J Dent Res 1999;78:447-452.

17. Ruddell D, Thompson J, Stamatiades P, Ward J, Bayne S, Shellard E. Mechanical properties and wear behavior of condensable composites. Dent Mater 1999;78:156.

18. Lindberg A, Peutzfeldt A, van Dijken JW. Effect of power density of curing unit, exposure duration, and light guide distance on composite depth of cure. Clin Oral Investig 2005 Jun;9(2):71-76.

19. Van Ende A, De Munck J, Van Landuyt KL, Poitevin A, Peumans M, Van Meerbeek B. Bulk-filling of high C-factor posterior cavities: effect on adhesion to cavity-bottom dentin. Dent Mater 2013 Mar;29(3):269-277.

20. Campodonico CE, Tantbirojn D, Olin PS, Versluis A. Cuspal deflection and depth of cure in resin-based composite restorations filled by using bulk, incremental and transtoothillumination techniques. J Am Dent Assoc 2011 Oct;142(10): 1176-1182.

21. Czasch P, Ilie N. In vitro comparison of mechanical properties and degree of cure of bulk fill composites. Clin Oral Investig 2013 Jan;17(1):227-235.
22. Ilie N, Bucuta S, Draenert M. Bulk-fill resin-based composites: an in vitro assessment of their mechanical performance. Oper Dent 2013 Nov-Dec;38(6):618-625.

23. Ilie N, Kessler A, Durner J. Influence of various irradiation processes on the mechanical properties and polymerisation kinetics of bulk-fill resin based composites. J Dent 2013 Aug;41(8):695-702.

24. Cao L, Zhao X, Gong X, Zhao S. An in vitro investigation of wear resistance and hardness of composite resins. Int J Clin Exp Med 2013 Jun;6(6):423-430.

25. DeLong R, Douglas WH. Development of an artificial oral environment for the testing of dental restoratives: bi-axial force and movement control. J Dent Res 1983 Jan;62(1):32-36.

26. De Gee AJ, Pallav P, Davidson CL. Effect of abrasion medium on wear of stress-bearing composites and amalgam in vitro. J Dent Res 1986 May;65(5):654-658.

27. Condon JR, Ferracane JL. Evaluation of composite wear with a new multi-mode oral wear simulator. Dent Mater 1996 Jul;12(4):218-226.

28. Leinfelder KF, Beaudreau RW, Mazer RB. An in vitro device for predicting clinical wear. Quintessence Int 1989 Oct;20(10): 755-761.

29. DeLong R. Intra-oral restorative materials wear: rethinking the current approaches: how to measure wear. Dent Mater 2006 Aug;22(8):702-711.

30. Heintze SD. How to qualify and validate wear simulation devices and methods. Dent Mater 2006 Aug;22(8):712-734.

31. Turbino ML, Belan LC, Soprano V, Rode KM, Lloret PR, Youssef MN. Argon ion laser curing depth effect on a composite resin. Lasers Med Sci 2011 Jul;26(4):421-425.

32. Say EC, Civelek A, Nobecourt A, Ersoy M, Guleryuz C. Wear and microhardness of different resin composite materials. Oper Dent 2003 Sep-Oct;28(5):628-634.

33. Kelsey WP 3rd, Blankenau RJ, Powell GL, Barkmeier WW, Cavel WT, Whisenant BK. Enhancement of physical properties of resin restorative materials by laser polymerization. Lasers Surg Med 1989;9(6):623-627.

34. Powell GL, Blankenau RJ. Laser curing of dental materials. Dent Clin North Am 2000 Oct;44(4):923-930.

35. Ruyter IE, Oysaed H. Conversion in different depths of ultraviolet and visible light activated composite materials. Acta Odontol Scand 1982;40(3):179-192.

36. Musanje L, Darvell BW. Curing-light attenuation in filled-resin restorative materials. Dent Mater 2006 Sep;22(9):804-817.

37. Mills RW, Jandt KD, Ashworth SH. Dental composite depth of cure with halogen and blue light emitting diode technology. Br Dent J 1999 Apr;186(8):388-391.

38. Shortall AC, Palin WM, Burtscher P. Refractive index mismatch and monomer reactivity influence composite curing depth. J Dent Res 2008 Jan;87(1):84-88.

39. Bhamra GS, Fleming GJ. Influence of halogen irradiance on short- and long-term wear resistance of resin-based composite materials. Dent Mater 2009 Feb;25(2):214-220.

40. Halvorson RH, Erickson RL, Davidson CL. Energy dependent polymerization of resin-based composite. Dent Mater 2002 Sep;18(6):463-469.

41. Ferracane JL. Is the wear of dental composites still a clinical concern? Is there still a need for in vitro wear simulating devices? Dent Mater 2006 Aug;22(8):689-692. 